Biogenic amines and phosphagens, two other important classes of "biochemicals", fare no better than the enzymes. In fact, as regards phosphagens, for example, except for a brief reference to their occurrence in invertebrate testes, there is no mention whatsoever, and I failed to discover in the text a single word about phosphocreatine in the mammalian testis.

The lipids and steroids are dealt with more thoroughly than other groups of testicular constituents. The chapter on lipids is well documented. That on the endocrinology of the testis, however, although rich in information, is rather heavily biased towards selected contributions, and rather strongly coloured by the author's personal idiosyncrasies, as evident from comments on the functional significance of the ratio of androstenedione to testosterone.

On the other hand, the contributions on the nucleic acids in the testis, and the in vitro growth and development of mammalian testis, are exceptionally useful. The latter chapter will, no doubt, be of great help to those who may have been wondering whether the gametogenic events of the living testis can really be reproduced in artificial conditions of culture in vitro. But many a biochemist will at the same time wonder why this particular chapter, which is largely concerned with problems of organ culture, should have been squeezed into a volume specifically devoted to biochemistry. One might perhaps also ask editors why a group of substances should be referred to in one chapter as DPN and TPN, and in another as NAD and NADP. And why doesn't the subject index include at least one single entry on biochemically important substances such as the cytochromes? T. MANN

\section{Underwater Blood}

Circulation in Fishes. By G. H. Satchell. (Cambridge Monographs in Experimental Biology, No. 18.) Pp. $x+131$. (Cambridge University: London, February 1971.) £2; $\$ 7$.

IN his preface to this latest addition to the Cambridge Monographs in Experimental Biology, Professor Satchell states that his purpose has been to attempt to integrate into a coherent account some of the information contained in the several thousand papers dealing with the structure and function of the vascular system of fishes. This difficult task has been well done, and the resulting monograph of 131 pages, which is a pleasure to read, can be warmly recommended. He cites 310 references, selected from material published between 1806 and 1970, but emphasizes that forty per cent of the papers given as references were published in or after 1965.
The subject matter is treated under eleven headings, including the heart, the arteries, the veins, the capillaries, the blood, the control of the heart and the response to hypoxia. A great deal of attention must have been given to what is a skilful grouping and arranging of material and undoubtedly this will help in making the book acceptable to the wide range of readers anticipated (from students in their last years at school to mammalian cardiovascular physiologists, who will find some interesting contrasts in many of the responses described). The text is supplemented by simple, clear figures and drawings.

The short, final chapter on future developments emphasizes the importance of the new "sophisticated" recording and measuring techniques which are becoming available to comparative physiologists (although "sophisticated" would seem to be a wrong description of these advanced techniques). One that is particularly worth mentioning is the use of telemetric recording of physiological information from free swimming fish in their natural environment. Professor Satchell also emphasizes the importance of information provided by the comparative physiologist for the fish cultivation industry, comparable with that available to the other meat-producing industries. It is as well that the pace of this type of research is increasing; there is much leeway to make up if the agricultural and fish cultivation industries are to be served equally in this respect.

\section{F. G. T. Holliday}

\section{Red Cell Membrane}

Red Cell Membrane: Structure and Function. Edited by G. A. Jamieson and Tibor J. Greenwalt. (The American National Red Cross Second Annual Scientific Symposium, Washington, DC, May 1969.) Pp. 384. (Lippincott: 1969. Distributed in UK by Blackwell: Oxford.) $£ 8.25$.

Bound in an appropriate bright red cover, this book contains the proceedings of a symposium sponsored by the American National Red Cross in May 1969. Although available for about a year in the United States, it has only just now reached Europe. As might be expected, the symposium covered almost every aspect bearing on the red cell membrane and in that sense was comprehensive. However, some of the authors have concentrated on their own research, while others have attempted to provide a review of their area. Interspersed between the fourteen chapters are six discussions-these are printed much as they must have occurredwhich provide some entertainment for the reader and, at times, help him to see in what the participants were inter ested and about what they were sceptical.

The first two chapters look at red cells or ghosts through the electron microscope. In the first, use is made of an ion etching technique which produces rather pretty pictures of sponge-like cells, the detail of which is likely to be artefactual rather than biologically significant. The second chapter shows and discusses several pictures of freezefractured and etched cells or ghosts together with what we now know is a mistaken interpretation of them. This makes the understanding of text and pictures a little difficult for the reader.

The next section, comprising the chemistry of the membrane, contains several good chapters. This starts with a short survey by Hanahan of some methods for fractionating membrane proteins. This line is pursued by Rosenberg and Guidotti as they describe their original approach to the separation and characterization of different proteins in the membrane. Marchesi and Steers and their colleagues discuss spectrin--that curious but fascinating protein which can be removed from ghosts by chelating agents and which can, in the presence of the right cations, form polymeric filaments. These are located on the inner surface of the cell membrane and are presumably a type of scaffolding to hold the cell in its characteristic shape.

Most of the cell's carbohydrate is found on the outer surface of the membrane, attached either as glycoprotein or glycolipid. The immunology of red cells-covered by Poulik and Bron-is intimately linked with the chemistry of these glyco-compounds. There seems to be just one major glycoprotein in the red cell membrane. As Winzler reported, it contains a hydrophobic polypeptide segment at one end which probably anchors the remainder of the glycoprotein in the membrane. This glycoprotein carries the $\mathrm{MN}$ cell antigens and is a most exciting component of the red cell. Most of the remainder of the cell surface carbohydrate is in the form of glycolipids, extensively covered by Sweeley and Dawson. This is a particularly valuable contribution to the book: it contains much of the chemistry known of these compounds (such as eicosasphing-4-eine-hard for all but the chemist), which are so likely to be of profound biological importance. As the authors note at the end, the three-dimensional structures of these compounds should be determined.

The rest of the book is about transport of molecules across the membrane and how the state of the membrane affects the physiology of the cell. This starts with a short chapter on the diffusion of gases through the membrane, followed by a lengthy section on the kinetics of monosaccharide transport by 